\title{
Randomised comparative study of ceftriaxone and spectinomycin in gonorrhoea
}

\author{
KANCHANA PANIKABUTRA, CHARAS ARIYARIT, ANUPONG CHITWARAKORN, \\ CHOOSAK SAENSANOH, AND CHAINARONG WONGBA \\ From the VD Control Division, Bangrak Hospital, Bangkok, Thailand
}

SUMMARY From 26 April to 30 June 1983 a total of 200 men with uncomplicated gonococcal urethritis were randomly treated with either $2 \mathrm{~g}$ spectinomycin or $250 \mathrm{mg}$ ceftriaxone, both administered intramuscularly. Of 197 isolates tested for the presence of the enzyme $\beta$ lactamase, 91 $(46 \cdot 2 \%)$ were positive (PPNG) and $106(53 \cdot 8 \%)$ were non-PPNG strains. All 93 patients treated with spectinomycin and followed up and 97 treated with ceftriaxone and followed up were cured. Ceftriaxone $250 \mathrm{mg}$ administered by intramuscular injection is highly effective in treating gonococcal infections caused by both PPNG and non-PPNG strains and is an appropriate alternative to spectinomycin.

\section{Introduction}

Ceftriaxone is a broad spectrum cephalosporin with an exceptionally long plasma elimination half life of about eight hours. ${ }^{12}$ It is the first long acting $\beta$ lactam antibiotic. The aminothiazole methoxyimino-acyl side chain gives the product good stability to $\beta$ lactamase. The bioavailability of ceftriaxone after intramuscular administration is $100 \%$. After injection, $60 \%$ of the drug is excreted in the urine and $40 \%$ is eliminated in the bile. ${ }^{3}$ Unlike many other cephalosporins, ceftriaxone is not excreted by tubular secretion. This is shown by the fact that probenecid has no effect on its elimination half life. ${ }^{4}$ It is a new third generation cephalosporin that has been found to be highly active against both PPNG and non-PPNG strains when compared with other cephalosporins of the same class. ${ }^{56}$ It is recommended for treating uncomplicated gonococcal infection in areas where PPNG strains are prevalent at a dose of $250 \mathrm{mg}$ administered intramuscularly. ${ }^{7}$

The study reported here was undertaken to compare the efficacy of ceftriaxone and spectinomycin in treating uncomplicated gonococcal urethritis in men caused by both PPNG and nonPPNG strains.

Address for reprints: Dr K Panikabutra, VD Control Division, Bangrak Hospital, 189 South Sathorn Road, Bangkok 10120, Thailand

Accepted for publication 18 May 1984

\section{Patients and methods}

STUDY DESIGN

We studied 200 Thai men who attended this hospital from 26 April to 30 June 1983 with uncomplicated gonococcal urethritis diagnosed by Gram stained smear microscopy at the initial visit to the clinic. They were randomly treated with either $2 \mathrm{~g}$ spectinomycin or $250 \mathrm{mg}$ ceftriaxone, both administered by intramuscular injection.

\section{DIAGNOSIS}

The diagnosis of gonorrhoea was based on the finding of Gram negative intracellular diplococci in Gram stained smears and on the results of cultures of material taken from the urethra. Blood was taken from each patient for routine serological tests for syphilis. The Gram stained smears were examined in the clinic; the other specimens were inoculated directly on to Thayer-Martin medium and incubated at $35^{\circ} \mathrm{C}$ in an atmosphere of carbon dioxide. Cultures were examined after 24 and 48 hours, and identification of Neisseria gonorrhoeae was based on typical colony morphology, a Gram stained smear showing Gram negative diplococci, and a positive oxidase test. Isolates were confirmed as being gonococci by sugar fermentation reactions. The colonies were subcultured to enumerate penicillinase producing strains of $N$ gonorrhoeae by the cephalosporin test. ${ }^{8}$ The confirmed gonococcal isolates were later tested for sensitivity to antibiotics by an agar plate dilution technique. ${ }^{9}$ 
FOLLOW UP

Follow up visits were arranged on days 3,7 , and 14 after treatment. On each occasion urethral material was obtained for Gram smear microscopy and culture. Routine serological tests for syphilis were performed at monthly intervals for three months.

If gonococci persisted or reappeared within 14 days of treatment and the patient had not had further sexual intercourse, then the treatment was considered to have failed; the reappearance of gonococci after 14 days irrespective of the patient's history, was considered to be due to reinfection. Those who had had sexual exposure before the first follow up examination were excluded from the final assessment.

Postgonococcal urethritis (PGU) was diagnosed if Gram stained smears of urethral material showed more than 4 leucocytes per microscope field $(\times 1000)$ seven days after treatment. ${ }^{10}$

STATISTICAL ANALYSIS

The unpaired $t$ test and the $\chi^{2}$ test were used.

\section{Results}

Of 200 patients enrolled in the study, 10 were excluded; three because $N$ gonorrhoeae could not be cultured, one because the patient had sexual intercourse before the first follow up, and six because the patients did not return for follow up examinations. Thus there were 93 patients treated with spectinomycin and 97 patients treated with ceftriaxone for evaluation. Table I shows the results of treatment; there were no failures in either group.

Of the 197 isolates with positive culture results tested for the presence of the enzyme $\beta$ lactamase, 91 $(46 \cdot 2 \%)$ were PPNG strains and $106(53 \cdot 8 \%)$ were non-PPNG strains.

\section{SENSITIVITY OF N GONORRHOEAE TO}

ANTIBIOTICS

Table II shows the minimum inhibitory concentrations (MICs) of spectinomycin and ceftriaxone for the 196 isolates of $N$ gonorrhoeae (91 PPNG, 105 non-PPNG) that were tested. The mean

TABLE I Results obtained with two schedules for treating uncomplicated urethral gonorrhoea in men

\begin{tabular}{|c|c|c|c|c|}
\hline & \multicolumn{2}{|c|}{ Spectinomycin } & \multicolumn{2}{|c|}{ Ceftriaxone } \\
\hline & $\begin{array}{l}\text { No } \\
\text { assessed }\end{array}$ & $\begin{array}{l}\text { No (\%) } \\
\text { cured }\end{array}$ & $\begin{array}{l}\text { No } \\
\text { assessed }\end{array}$ & $\begin{array}{l}\text { No (\%) } \\
\text { cured }\end{array}$ \\
\hline $\begin{array}{l}\text { PPNG } \\
\text { Non-PPNG }\end{array}$ & $\begin{array}{l}48 \\
45\end{array}$ & $\begin{array}{l}48(100) \\
45(100)\end{array}$ & $\begin{array}{l}42 \\
55\end{array}$ & $\begin{array}{l}42(100) \\
55(100)\end{array}$ \\
\hline Total & 93 & $93(100)$ & 97 & $97(100)$ \\
\hline
\end{tabular}

PPNG = penicillinase producing Neisseria gonorrhoeae.
MIC of spectinomycin was $8.54 \mathrm{mg} / 1$ for PPNG strains and $8.12 \mathrm{mg} / 1$ for non-PPNG strains $(t=1.516 ; \mathrm{p}>0.01)$. The mean MIC of ceftriaxone was $0.005 \mathrm{mg} / 1$ for PPNG strains and $0.004 \mathrm{mg} / 1$ for non-PPNG strains $(t=2 \cdot 67 ; \mathrm{p}<0 \cdot 01)$.

TABLE II Sensitivity of 196 isolates of Neisseria gonorrhoeae to antibiotics

\begin{tabular}{|c|c|c|c|c|}
\hline \multirow[b]{2}{*}{$M I C(m g / l)$} & \multicolumn{2}{|c|}{ Spectinomycin } & \multicolumn{2}{|c|}{ Ceftriaxone } \\
\hline & $P P N G$ & Non-PPNG & $P P N G$ & Non-PPNG \\
\hline $\begin{array}{c}0.001 \\
0.002 \\
0.004 \\
0.008 \\
0.016 \\
5.0 \\
7.5 \\
10.0 \\
15.0\end{array}$ & $\begin{array}{r}8 \\
45 \\
34 \\
4\end{array}$ & $\begin{array}{r}13 \\
55 \\
36 \\
1\end{array}$ & $\begin{array}{r}4 \\
19 \\
40 \\
24 \\
4\end{array}$ & $\begin{array}{r}17 \\
33 \\
38 \\
15 \\
2\end{array}$ \\
\hline Total & 91 & 105 & 91 & 105 \\
\hline$\underset{(\mathrm{mg} / \mathrm{l})}{\operatorname{Mean} \text { MIC }}$ & $8 \cdot 54$ & $8 \cdot 12$ & 0.005 & 0.004 \\
\hline
\end{tabular}

PPNG $=$ penicillinase producing $N$ gonorrhoeae .

\section{SIDE EFFECTS}

No side effects to either drug were reported by the patients or noted on examination.

\section{POSTGONOCOCCAL URETHRITIS (PGU)}

Of 85 men treated with spectinomycin who attended for follow up on day 7 after treatment, 31 (36.5\%) had PGU. Of 85 men treated with ceftriaxone who attended for follow up on day $7,34(\mathbf{4 0 \%})$ had developed PGU. The difference between the two groups was not significant $\left(\chi^{2}=0.225 ; p>0.01\right)$.

\section{Discussion}

In areas where $\beta$ lactamase producing gonococci are prevalent penicillin should not be used to treat gonococcal infections. Spectinomycin, cefoxitin, cefotaxime, and ceftriaxone have been recommended. ${ }^{7}$ Although there are reports from various parts of the world, including Thailand where PPNG strains are endemic, showing that spectinomycin, cefoxitin, and cefotaxime are effective in treating such infections, alternative treatments should be encouraged. ${ }^{11-18}$ Since 1981 PPNG strains resistant to spectinomycin have been reported. ${ }^{19} 20$

Ceftriaxone is a new third generation cephalosporin that has been found to be active against both PPNG and non-PPNG strains. ${ }^{56}$ In the study published here the non-PPNG strains were more susceptible than PPNG strains to ceftriaxone, a finding noted previously by Thabaut et al. ${ }^{6}$ The 
treatment of uncomplicated gonococcal infection with 125-250 mg ceftriaxone in both men and women has shown $100 \%$ efficacy. ${ }^{21-26}$ Rajan et al also reported a cure rate of $100 \%$ in treating gonorrhoea with ceftriaxone $125 \mathrm{mg}$ and probenecid $1 \mathrm{~g} .{ }^{27}$ In our study we found that ceftriaxone at a dose of $250 \mathrm{mg}$ administered intramuscularly without probenecid was highly effective for infections with both PPNG and non-PPNG strains. The patients tolerated the drug well and no one complained of pain at the site of injection. We conclude that ceftriaxone is an appropriate alternative to spectinomycin and other cephalosporins in treating gonorrhoea.

We thank the Roche Far East Research Foundation and Roche Thailand for providing the ceftriaxone used in this study.

\section{References}

1. Angehrn P, Probst PJ, Reiner R, Then RL. Ro 13-9904, a long-acting broad-spectrum cephalosporin: in vitro and in vivo studies. Antimicrob Agents Chemother 1980; 18:913-21.

2. Patel IH, Chen S, Parsonnet M. Pharmacokinetics of ceftriaxone in humans. Antimicrob Agents Chemother 1981; 20:634-41.

3. Stoeckel K. Pharmacokinetics of Rocephin, a highly active new cephalosporin with an exceptionally long biological half-life. Chemotherapy $1981 ; 27$ suppl 1:42-6.

4. Stoeckel K, McNamara PJ, Brandt R, Ziegler WH. The influence of protein binding on the pharmacokinetics of 'Rocephin' Roche. Proceedings of the 12th International Congress of Chemotherapy. Florence, 19-24 July 1981.

5. Prere MF, Lefervre JC, Lareng MB. Study of the in-vitro activity of new cephalosporins on strains of the Toulouse region. Chemotherapy 1981;27 suppl 1:15-8.

6. Thabaut A, Durosoir JL, Saliou P. Comparative in-vitro activity of eight cephalosporins on 109 strains of $N$ gonorrhoeae and 60 strains of $N$ meningitidis. Chemotherapy 1981;27 suppl $1: 19-24$.

7. WHO Consultative Group. Current treatments in the control of sexually transmitted diseases. WHO/VDT/83 1983;433:1-7.

8. World Health Organisation. Neisseria gonorrhoeae and gonococcal infections. WHO Tech Rep Ser 1978; No 616:138-9.

9. Jaffe HW, Biddle JW, Thornsberry C, et al. National gonorrhea therapy monitoring study: in vitro antibiotic susceptibility and its correlation with treatment results. $N$ Engl J Med 1976; $294: 5-9$.

10. World Health Organisation. Non gonococcal urethritis and other selected sexually transmitted diseases of public health importance. WHO Tech Rep Ser 1981; No 660:59.
11. Panikabutra $\mathrm{K}$, Ariyarit $\mathrm{Ch}$, Chitwarakorn A, Warnissorn $\mathrm{T}$, Saensanoh Ch. Sensitivity to penicillin, thiamphenicol, kanamycin, cefoxitin and spectinomycin of PPNG in Bangkok. Relation to the results of treatment. J Med Assoc Thai 1982;65:316-24.

12. Kaufmann RE, Johnson RE, Jaffe HW, et al. National gonorrhea monitoring study: treatment results. $N$ Engl J Med 1976; 294: 1-4.

13. Jones RB, Stimson J, Counts GW, Holmes KK. Cefoxitin in the treatment of gonorrhea. Sex Transm Dis 1979;6:239-42.

14. Berg SW, Kilpatrick ME, Harrison WO, McCutchan JA. Cefoxitin as a single-dose treatment for urethritis caused by penicillinase producing Neisseria gonorrhoeae. $N$ Engl J Med 1979; 301:509-11.

15. Hard S, Moberg I, Wennberg K. Single dose treatment of gonococcal urethritis in males with cefotaxime in different concentrations. Asian Journal of Clinical Sciences 1980; 1:307-10.

16. Rajan VS, Sng EH, Pang R, Tan NJ, Thirumoorthy T, Yeo KL. HR 756-a new cephalosporin in the treatment of gonorrhoea caused by ordinary and penicillinase producing strains of Neisseria gonorrhoeae. British Journal of Venereal Diseases 1980;56:255-8.

17. Hansfield HH, Holmes KK. Treatment of uncomplicated gonorrhea with cefotaxime. Sex Transm Dis 1981;8:187-91.

18. Panikabutra K, Ariyarit Ch, Chitwarakorn A, Warnissorn T. Cefotaxime in the treatment of gonorrhoea caused by PPNG and non PPNG. J Med Assoc Thai 1982;65:271-6.

19. Adams H, Ashford W, Potts DW, San Diego A, Chong V, Grant D. Spectinomycin resistant penicillinase-producing Neisseria gonorrhoeae California. MMWR 1981;30:221-2.

20. Kim JH, Han GC, Hong SW, Junn JW. Spectinomycin resistant PPNG. Journal of the Korean Medical Association 1982; 25: 1117-20.

21. Hansfield HH, Murphy VL, Holmes KK. Dose-ranging study of ceftriaxone for uncomplicated gonorrhea in men. Antimicrob Agents Chemother 1981; 20: 839-40.

22. Judson FN, Ehret JM, Roor CJ. Comparative study of ceftriaxone and aqueous procaine penicillin $\mathrm{G}$ in the treatment in uncomplicated gonorrhea in women. Antimicrob Agents Chemother 1982;23:218-20.

23. Zajdowicz TR, Sanches PL, Berg SW, Kerbs SBJ, Newquist RL, Harrison WO. Comparison of ceftriaxone with cefoxitin in the treatment of penicillin-resistant gonococcal urethritis. British Journal of Venereal Diseases 1983;59: 176-8.

24. Eichmann A, Weidman G, Havas L. One-dose treatment of acute uncomplicated gonorrhoea of male patients with ceftriaxone RO 13-9904, a new parenteral cephalosporin: a doserange finding pilot study using doses of $500,250,125$, and $50 \mathrm{mg}$ respectively, in descending order. Chemotherapy 1981;27 suppl 1:62-9.

25. Gismarellou H, Poulopoulos B, Katsabas A, Petrikkos G, Papapetropoulou M, Diakos GK. Antibacterial activity of RO 13-9904 and preliminary experience in gonorrhoea and chronic urinary tract infections. Chemotherapy 1981;27 suppl 1:70-4.

26. Handsfield HH, Murphy VL. Comparative study of ceftriaxone and spectinomycin for treatment of uncomplicated gonorrhoea in men. Lancet 1983; ii:67-70.

27. Rajan VS, Sng EH, Thirumoorthy T, Goh CL. Ceftriaxone in the treatment of ordinary and penicillinase-producing strains of Neisseria gonorrhoeae. British Journal of Venereal Diseases 1982; 58:314-6. 